\title{
Bioética global na perspectiva da bioética crítica
}

\section{Resumo}

Desde os anos 1990 a bioética tem se aproximado cada vez mais das discussões internacionais relacionadas à saúde e às ciências da vida, o que levou alguns autores a referir-se à "bioética global". O presente artigo analisa este conceito tal como elaborado nas perspectivas de três formulações teóricas da bioética norteamericana: a de Van Rensselaer Potter, a de Tristam Engelhardt e a de Beauchamp e Childress. Ao balancear as potencialidades e as insuficiências das abordagens destes autores, propõe a "bioética crítica" como alternativa teórica melhor capacitada para enfrentar os temas globais da bioética a partir da perspectiva histórica dos países do Sul global.

Palavras-chave: Bioética. Bioética global. Crítica. Saúde global.

\section{Resumen}

\section{Bioética global desde la perspectiva de la bioética crítica}

Desde la década de 1990 la bioética se ha acercado cada vez más a los debates relacionados con las ciencias de la vida y la salud internacional, lo que llevó a algunos autores a referirse a la "bioética global". En este artículo se examina este concepto desarrollado en las perspectivas teóricas de tres formulaciones de la bioética estadunidense: Van Rensselaer Potter, Tristram Engelhardt y Beauchamp y Childress. Al evaluar las fortalezas y debilidades de los enfoques de estos autores, propone la "bioética crítica" como una alternativa teórica más cualificada para hacer frente a los problemas mundiales de la bioética desde la perspectiva histórica de los países del Sur global.

Palabras-clave: Bioética. Bioética global. Crítico. Salud global.

\begin{abstract}
Global bioethics from the perspective of critical bioethics

Since the 1990s bioethics has increasingly approached the discussions related to international health and life sciences, which led some authors to refer to the "global bioethics". This article examines this concept as elaborated in the theoretical perspectives of three formulations of North American bioethics: Van Rensselaer Potter, the Tristram Engelhardt, and Beauchamp and Childress. By balancing the strengths and weaknesses of the approaches of these authors, it is proposed the "critical bioethics" as the best qualified alternative theoretical to address the global issues of bioethics from the historical perspective of the countries of the Global South. Key words: Bioethics. Global bioethics. Critical. Global health.
\end{abstract}

1. Doutorando caixadothiago@gmail.com 2. Doutor claudiolorenzo.unb@gmail.com - Universidade de Brasília, Brasília/DF, Brasil.

\section{Correspondência}

Thiago Cunha - Campus Universitário Darcy Ribeiro. Faculdade de Ciências da Saúde. Programa de Pós-Graduação em Bioética CEP 70910-900. Brasília/DF, Brasil.

Declaram não haver conflito de interesse. 
Com a intensificação do processo de globalização após os anos 1990, a bioética passou a abordar os conflitos éticos das ciências da vida e da saúde em escala cada vez mais global. Recentemente, a consolidação de novo campo de práticas, políticas e estudos denominado "saúde global" trouxe novos desafios à disciplina, especialmente para sua epistemologia tradicional, historicamente vocacionada à análise de microproblemas e conflitos morais biomédicos e biotecnológicos ${ }^{1,2}$.

Os desafios decorrem de uma peculiaridade da saúde global, cuja conceituação exige reconhecer, ao menos descritivamente, as profundas desigualdades nas condições de saúde e doença entre diferentes populações do globo. Desde um ponto de vista prescritivo, impõe a reflexão sobre as responsabilidades éticas da comunidade internacional tanto na manutenção das condições estruturais que perpetuam as desigualdades globais em saúde quanto na transformação dessas condições.

Frente a este cenário, o presente artigo analisa a chamada bioética global na perspectiva de três formulações teóricas estadunidenses com reconhecida importância ao campo: a de Van Rensselaer Potter, a de Tristam Engelhardt e a de Beauchamp e Childress. Para tanto, foi desenvolvida uma pesquisa teórica a partir das orientações metodológicas de Pedro Demo, para quem esse tipo de estudo permite reconstruir teoria, conceitos, ideias, ideologias, polêmicas, tendo em vista, em termos imediatos, aprimorar fundamentos teóricos ${ }^{3}$.

Ao comparar e discutir os potenciais e as insuficiências das formulações de Potter, Engelhardt e Beauchamp e Childress, o artigo propõe a abordagem da "bioética crítica" como uma alternativa teórica mais apropriada para a análise de temas globais da bioética e da saúde desde a perspectiva histórica dos países do Sul global.

\section{Bioética em perspectiva global}

Como delineada em 1970 por Van Rensselaer Potter, a bioética propôs uma reflexão moral sobre o desenvolvimento da ciência e da tecnologia e seu impacto à sobrevivência da vida planetária, o que já lhe atribuiu, desde o nascimento, uma vocação eminentemente global ${ }^{4}$. Mais do que um novo campo de estudos, Potter delineou a bioética como uma ponte para o futuro, uma ciência da sobrevivência humana, visualizando-a como novo campo de militância global. Foi neste sentido de forte engajamento planetário que propôs os cinco credos bioéticos, cuja identificação e filiação seriam fundamentais para quem buscasse se aproximar da nova "ciência" 4.

Todavia, a bioética ponte não foi encampada pela comunidade científica ou por movimentos sociais, de modo que a abordagem não teve uma repercussão imediata significativa. Um dos motivos para o ocaso da bioética potteriana pode ser atribuído à redução principialista, ocorrida a partir do final dos anos 1970, quando a bioética se consolidou como disciplina estritamente biomédica vocacionada a orientar conflitos morais mediante processos e princípios pré-estabelecidos, tal como influenciada pelos trabalhos de Beauchamp e Childress ${ }^{5}$.

A partir dos anos 1980 essa versão reducionista da bioética expandiu-se dos Estados Unidos da América (EUA) para os demais países, e mesmo com as tentativas, nos anos 1990, da International Association of Bioethics para "resgatar" a perspectiva inicial de Potter, o campo só veio a apresentar uma característica realmente global a partir de 2005, com a publicação da Declaração Universal sobre Bioética e Direitos Humanos (DUBDH) pela Organização das Nações Unidas para a Educação, a Ciência e a Cultura (Unesco) ${ }^{6}$.

Além de aproximar a bioética ao universalismo dos direitos humanos, o que já seria suficiente para caracterizar uma expansão global, os temas e princípios incluídos no documento privilegiaram tomadas de ações coordenadas em nível internacional e sustentadas por valores universais, tais como a dignidade, a justiça, a equidade, a cooperação e a solidariedade. O artigo 14 - Responsabilidade Social e Saúde - reafirma que o desenvolvimento social e o acesso ao mais alto padrão de saúde atingível são objetivos centrais dos governos que devem ser partilhados por todos os setores da sociedade. Segundo relatório sobre o tema, publicado pela International Bioethics Committee of Unesco, esse dever inclui toda a população mundial, inclusive setores e instituições não governamentais ${ }^{7}$.

O fundamento moral para esta responsabilidade globalmente compartilhada decorre da compreensão de que vivemos em um contexto cada vez mais internacionalizado, no qual as determinações da saúde não dependem apenas de decisões individuais ou mesmo de governos particulares, mas de complexas relações políticas, econômicas, sociais e culturais que repercutem em fenômenos sistemáticos, tais como a pobreza, a má alimentação, o desemprego e as mudanças climáticas ${ }^{7,8}$. Principalmente, e para além das relações sociais internacionalizadas, a responsabilidade moral global decorre 
do reconhecimento de que a Terra é geologicamente um sistema vivo único (Sistema Terra) cujo destino é invariavelmente compartilhado por todos os seus membros atuais e futuros.

Paralelamente à publicação da Declaração Universal sobre Bioética e Direitos Humanos, o retorno a uma perspectiva global da bioética - ainda que não necessariamente realizada nos marcos propostos por Potter - deve-se, segundo ten Have e Gordijn $^{9}$, a dois fatores principais: 1) expansão institucional da disciplina por meio de congressos e programas de ensino internacionais; 2) abordagem de temas eminentemente globais, sobretudo as pesquisas transnacionais envolvendo seres humanos. Para todos os fins, a bioética desenvolvida pioneiramente na perspectiva de Potter ${ }^{1}$ já apresentava característica eminentemente global, consolidada em publicações posteriores do autor ${ }^{10-12}$, tal como destacado a seguir.

\section{Bioética global na perspectiva de Potter}

No final dos anos 1980, Potter propôs a expansão da bioética ponte para uma bioética global ${ }^{9}$, cujo foco deveria ser ainda mais interdisciplinar para que a nova ciência pudesse cumprir seu objetivo de garantir a sobrevivência humana. Mas Potter não se referia a qualquer sobrevivência; apenas às "bioeticamente" defensáveis. Nesse sentido, distinguiu cinco estados de sobrevivência global: 1) mera sobrevivência; 2) sobrevivência miserável; 3) sobrevivência idealista; 4) sobrevivência irresponsável e; 5) sobrevivência aceitável ${ }^{10,11}$.

Mera sobrevivência implica o cenário no qual os seres humanos buscam apenas a manutenção de suas necessidades básicas - alimento, abrigo e manutenção reprodutiva - em um sistema social baseado na caça e coleta, ou seja, que não dispõe de qualquer "progresso" para além desse estado, considerando o progresso como o desenvolvimento de técnicas como a escrita, a leitura, as cidades etc.

Em artigo publicado com sua neta, Lisa, em 1995, Potter ${ }^{11}$ discutiu o exemplo dos inuits isolados para indicar que este estado não é moralmente inferior aos estados de sobrevivência em que há progresso cultural. Nesse trabalho considerou que embora aquele grupo (chamado pejorativamente pelos colonizadores de "esquimós") possa ser identificado como vivendo em mera sobrevivência, usufrui seu próprio conceito do que seria uma sobrevivência bioética, baseada no reconhecimento de deveres com o meio ambiente e no sentimento coletivo de orgulho sobre suas constituições históricas e sociais. O mesmo exemplo se aplicaria às chamadas "sociedades primitivas", como os nômades dos desertos africanos ou os ianomâmis da Amazônia ${ }^{10}$.

Um conflito ético surge, no entanto, quando as sociedades primitivas passam do estado da mera sobrevivência para a sobrevivência miserável como resultado da invasão dos colonos brancos ${ }^{13}$. Segundo Potter, a sobrevivência miserável é a condição em que as sociedades estão sob os danos disseminados pelas doenças, guerras e destruição ambiental produzidas pelas ações antrópicas. Este é o estado em que potencialmente vive mais da metade da população planetária, incluindo pessoas do Sul e do Norte global, já que a sobrevivência miserável pode ser encontrada nos bolsões de todo o mundo, incluindo os EUA ${ }^{14}$.

A sobrevivência idealista pressupõe o acordo universal sobre a melhor forma de sobrevivência planetária: há o entendimento tácito compartilhado por todas as culturas baseado na compreensão da conveniência da saúde em contraponto à inconveniência da doença evitável. Potter acredita que esta razoabilidade universal seria possível, já que, por exemplo, nenhuma cultura ou religião, primitiva ou moderna, jamais premiou ou aspirou à fome, desnutrição, diarreia, ou as infestações parasitárias ${ }^{14}$.

Por sua vez, a sobrevivência irresponsável é o oposto da sobrevivência idealista e da sobrevivência aceitável. Caracteriza-se pelos grupos sociais que se reproduzem de geração em geração sem considerar o sofrimento da sobrevivência miserável, que atinge outros grupos sociais e que potencialmente atingirá gerações futuras. Neste estado pratica-se consumo excessivo, estimula-se a superpopulação, a degradação da biosfera e o empobrecimento progressivo dos miseráveis. O modelo econômico mundial representado pela cultura dominante nos EUA é responsabilizado por Potter como a causa da atual situação de sobrevivência irresponsável ${ }^{10,11}$.

Por fim, a sobrevivência aceitável é defendida como a meta da bioética global. É o estado que tem por base moral a garantia da dignidade humana, dos direitos humanos universais, inclusive do direito à saúde, e da restrição moral da fertilidade humana por meio de controles voluntários. A sobrevivência aceitável compreende a espécie humana no contexto da totalidade da sobrevivência da biosfera. Sob este aspecto, Potter destaca que a expansão dominante, mas irresponsável, da cultura mundial não é um tipo aceitável de desenvolvimento, pois não pode sobreviver no longo prazo ${ }^{15}$. 
Potter ${ }^{9,10}$ aponta como principais desafios à sobrevivência global aceitável duas formas de fundamentalismos: a sacralidade da vida, ilustrada no fundamentalismo religioso que impede a discussão pública sobre a necessidade do controle de natalidade em nível global, e a sacralidade do dólar, que impede a discussão sobre modelos de desenvolvimento que não estejam baseados na ideia de crescimento econômico e material descontrolado.

Ao lado de Lisa Potter, o autor pontuou: Qualquer pessoa que se preocupa com a sobrevivência global da espécie humana em longo prazo deve estar ciente da relação entre o aumento da população, o esgotamento de recursos, as guerras étnicas e religiosas atuais e futuras e que é o 'todo-poderoso dólar' que impulsiona o comércio internacional de armas e combustiveis nestes conflitos ${ }^{16}$. Com tal percepção crítica, destacou ainda que no estado de sobrevivência aceitável não é possível justificar a violação da proteção à dignidade, à saúde e aos direitos humanos em nome de liberdades pessoais, dado que as reivindicações particulares e irrestritas podem prejudicar as gerações futuras e as pessoas no estado de miséria da contemporaneidade. Conclui, por isso, ser dever da bioética global desafiar o pensamento econômico que coloca em risco a sobrevivência aceitável.

Em outro artigo da década de 1990, Potter, agora sozinho ${ }^{12}$, criticou a bioética médica produzida nos EUA. Assinalou que sua abordagem recai nos mesmos problemas de outras especialidades médicas, a saber, a busca pela saúde perfeita e a fragmentação do conhecimento, características que tornaram a bioética muito paroquial: Paroquial, pois a busca americana ignora os problemas de saúde das multidões em outras partes do mundo; ela deveria, em vez disso, buscar pela "saúde humana como a bioética global" no contexto da sobrevivência e da melhoria de toda a raça humana, e não apenas de alguns poucos escolhidos ${ }^{17}$.

Em contraponto, reforçou a proposta de uma bioética global próxima à ética social e em oposição à ética econômica ou capitalista, à medida que a primeira está associada aos direitos dos trabalhadores, controle voluntário da reprodução humana, regulação das classes mais privilegiadas, proteção dos mais desfavorecidos, saúde no mundo, dignidade humana e justiça ${ }^{17}$. Potter destacou ainda que enquanto a proposta inicial de sua bioética foi a construção de uma ponte entre os conhecimentos humanos e biológicos, a nova abordagem da bioética global propõe que a ponte se estenda entre as próprias éticas fragmentadas, especialmente entre a ética médica, a ética social e as éticas ecológicas ${ }^{12}$.
Bioética global na perspectiva de Tristam Engelhardt

Recentemente, Tristam Engelhardt também passou a problematizar a bioética a partir da alcunha "global". Na coletânea Global bioethics: the collapse of consensus ${ }^{18}$, da qual foi organizador, discutiu a partir da negação da possibilidade de qualquer consenso moral universal baseado no paradigma do pensamento moderno da racionalidade discursiva, ou seja, com base no argumento secular, racional e lógico ${ }^{19}$. Segundo o autor, essa impossibilidade decorre do fato de diferentes comunidades morais do globo discordarem - e muitas vezes disputarem acerca da definição de premissas básicas e de regras de evidência sobre temas morais. Ou seja, o conflito ético não se daria apenas quanto à definição de práticas moralmente corretas ou verdadeiras, mas quanto ao caráter de base da própria moralidade ${ }^{19}$.

Nesse sentido, Engelhardt refutou inclusive a validade moral dos direitos humanos. Criticando especificamente a Declaração Universal sobre Bioética e Direitos Humanos da Unesco como promotora da bioética global, afirmou que o documento constitui um conjunto de princípios vazios incapaz de considerar seriamente a disparidade moral característica da era contemporânea ${ }^{20}$. Esse ponto de vista irá subsidiar seu posicionamento e o de outros autores da coletânea a respeito de temas como a ilegitimidade da constituição de sistemas públicos de saúde nacional ou global, uma vez que obrigaria todas as comunidades morais a compartilhar um pressuposto particular sobre a solidariedade ou o altruísmo. A respeito, DelkeskampHayes expressa que a garantia dos direitos sociais é incompativel com os direitos de independência ${ }^{21}$.

Concordando com essa perspectiva, Engelhardt afirmou que o reconhecimento do caráter inerradicável do pluralismo moral fornece bases substantivas para a rejeição de argumentos a favor de uma única moralidade e bioética universal plena de conteúdo a ser concretizada por meio de legislação internacional e políticas públicas ${ }^{22}$. Por isso, estaria fadada ao fracasso qualquer tentativa de edificar uma bioética global com bases em uma moralidade universal comum. Erickson também ratifica essa perspectiva considerando que não é fácil prever o efeito de projetos fracassados, tais como o de uma 'bioética global', muito embora passos possam ser dados a fim de atenuar ou evitar por completo as consequências mais destrutivas que tais fracassos geralmente engendram ${ }^{23}$.

A crítica à possibilidade de qualquer bioética global substantiva (plena de conteúdo) também será 
subterfúgio para que Engelhardt defenda a saúde e a própria moralidade como produtos a serem definidos por meio de procedimentos contratuais entre agentes supostamente autônomos. O autor destaca que na melhor das hipóteses há modalidades procedimentais de colaboração que permitem negociação e acordo limitado, como nos mercados. O paradigma para a discussão política torna-se não aquele do seminário socrático, mas o de um mercado limitado, no qual há intercâmbios pacíficos de acordo ${ }^{20}$. Ou seja, a bioética global na perspectiva engelhardtiana deve ser necessariamente fundada em uma ética procedimental mantida por acordos pacíficos entre participantes de um mercado de interesses morais ${ }^{23}$ estabelecidos mediante apenas três restrições:

a) jamais usar pessoas sem a permissão delas (desde que as pessoas se conformem a esta prática; por exemplo: uma pessoa pode defender-se contra o assassinato);

b) jamais agir mal-intencionado;

c) tentar (como elaboração posterior de "a" e "b") agir prudentemente no sentido de buscar a realização de mais benefício que dano (e sem qualquer pretensão de acordo entre comunidades morais relativo à natureza dos danos e benefícios, ou de como eles deveriam ser comparados) ${ }^{24}$.

Wildes, autor do último capítulo da coletânea, acrescenta que mesmo se houvesse um acordo significativo na esfera global a partir dessas bases procedimentais não seria possível estabelecer juízos morais comuns, a função que estaria no coração da bioética ${ }^{25}$. Destarte, ao negar qualquer conteúdo universal sobre o correto, o bem ou a virtude e relegar a definição axiológica aos limites das comunidades morais particulares, Engelhardt, seguido pela maioria dos autores do livro, postulou que a perspectiva procedimental é a única adequada para uma bioética global preocupada com o pluralismo moral radical identificado na pós-modernidade ${ }^{18}$.

\section{Bioética global na perspectiva de Beauchamp e Childress}

Ao contrário de Engelhardt, Beauchamp e Childress ${ }^{5}$ defenderam não apenas a possibilidade, mas a existência factual de uma "moralidade comum universal" cujo núcleo normativo não é relativo às culturas, comunidades ou indivíduos, haja vista que $a$ moralidade comum é a aplicada as todas as pessoas, em todos os lugares, e nós podemos corretamente julgar toda conduta humana por esses padrões ${ }^{25}$. Segundo os autores, essa moralidade universal é produto histórico da experiência humana, e não uma propriedade a-histórica ou a priori, tal como são compreendidas as moralidades universais em certas perspectivas metafísicas/religiosas.

A moralidade comum resultaria da transmissão de práticas e ensinamentos ao longo do tempo entre diversas comunidades morais constituídas por pessoas que vivem uma vida moral ${ }^{26}$. Entre outras, algumas normas derivadas deste "núcleo" da moralidade seriam, por exemplo: "não matar", "manter promessas", "salvar pessoas em perigo", "dizer a verdade", "alimentar a criança ou dependente", "não punir o inocente". Contudo, se a moralidade comum constitui-se como o conjunto de normas universais, abstratas e "fracas de conteúdo", Beauchamp e Childress ${ }^{5}$ defendem que existe outro nível ético constituído por moralidades particulares, com normas não universais, concretas, e "ricas de conteúdo". Essas moralidades particulares se expressam em diversas comunidades, tradições, religiões e práticas profissionais, e se distinguem entre elas apenas pelas especificidades na aplicação das normas universais, o que significa que nenhuma moralidade particular pode justificar a violação da moralidade comum universal.

Além dessa abordagem epistemológica que associa Beauchamp e Childress a uma discussão conceitual sobre a bioética global desde as primeiras edições do livro Principles of biomedical ethics, os autores incluíram nas últimas edições algumas reflexões pontuais sobre a saúde global no contexto da aplicação do princípio da justiça. Analisando as abordagens de teorias recentes de Peter Singer ("utilitarismo beneficente cosmopolita"), Martha Nussbaum ("abordagem das capacidades como teoria da justiça"), e Thomas Pogge ("aplicação global da teoria de Rawls"), Beauchamp e Childress ponderaram que o princípio da justiça exige o reconhecimento universal do direito a um mínimo decente de cuidados em saúde ${ }^{27}$.

Embora o direito mínimo à saúde - que segundo os autores inclui medidas de saúde pública, saneamento, acesso à água limpa e correlatos - seja tipicamente associado às políticas nacionais, Beauchamp e Childress defenderam que no atual contexto de globalização econômica o princípio da justiça eleva o direito à esfera global. Em suas palavras: um mundo globalizado trouxe a percepção de que a proteção e a manutenção das condições de saúde são de natureza internacional e exigirá uma reestruturação justa da ordem global ${ }^{28}$.

Ressaltam que a abordagem da justiça global não deve focar apenas a questão dos cuidados de 
saúde, mas, sobretudo, atuar nas "causas" das doenças e das iniquidades na distribuição dos serviços e cuidados em saúde, o que incluiria temas como acesso à educação e outras dimensões do bem-estar. Mais do que isso, exigiria reconhecer que muitas das causas dessas iniquidades na distribuição da saúde não resultam meramente de dificuldades relacionadas à má sorte ou aos fracassos pessoais, pelo contrário, são frequentemente distribuídas por instituições sociais, as quais podem ser estruturadas explicitamente para reduzir tais desigualdades ${ }^{29}$.

No entanto, sob a justificativa de uma postura realista da aplicação do "direito mínimo à saúde", Beauchamp e Childress propõem o reconhecimento dos direitos globais a um mínimo decente de cuidados de saúde dentro de um quadro de alocação que incorpora tanto as normas utilitaristas quanto igualitárias ${ }^{30}$. Isto significa que para garantir a "eficiência e a utilidade" de um sistema universal para viabilização do direito mínimo à saúde, seriam necessários cortes de gastos na alocação de recursos que, por sua vez, poderiam ser compensados com a promoção de incentivos a hábitos saudáveis e com a responsabilização por comportamentos de riscos não saudáveis dos beneficiários do direito.

Assim, embora Beauchamp e Childress não se refiram diretamente ao termo bioética global - até porque seu foco não é a bioética, mas a ética biomédica - algumas abordagens do princípio da justiça os aproximam das discussões sobre bioética e saúde global, e igualmente no âmbito teórico-conceitual com as análises sobre a moralidade comum universal.

\section{Bioética global na perspectiva da bioética crítica}

Chamamos "bioética crítica" a formulação teórica que conjuga a teoria crítica de Frankfurt e os estudos sobre colonialidade como ponto de partida para a fundamentação teórico-conceitual da bioética, tal como recentemente delineada ${ }^{31,32}$. É importante destacar que nem todo pensamento crítico ou crítica social se constituem teoria crítica. Se considerarmos o pensamento crítico como oposição à hegemonia dos discursos sustentados na exclusão das diferenças e na negação da alteridade, próprios às ideologias de dominação ${ }^{33}$, então outros modelos teóricos de bioética que vêm sendo desenvolvidos na América Latina poderiam ser consideradas bioéticas críticas, em especial a bioética de proteção de Kottow e Schramm ${ }^{34}$ e a bioética de intervenção de Garrafa e Porto ${ }^{35}$, dado que ambas se opõem aos discursos hegemônicos reducionistas em bioética e fazem a opção de analisar e propor soluções para conflitos éticos no campo da saúde e ambiente envolvendo os grupos sociais excluídos ou vulnerados no percurso da relação histórica entre ciência e capital.

O termo "crítica" de nossa proposição, entretanto, não é adjetivo, e sim substantivo, vez que indica sua fundamentação a partir da teoria social, chamada "crítica", que vem se desenvolvendo ininterruptamente ao longo dos últimos 80 anos e que dispõe de conceitos e princípios bem definidos que as diferencia de outras críticas sociais. A proposta da chamada escola de Frankfurt era tomar como ponto de partida a teoria econômica e social de Marx, sem se prender dogmaticamente às suas análises, e engendrar estudos interdisciplinares que contribuíssem para a elaboração de ações com vistas à emancipação dos grupos sociais explorados ou excluídos pela organização capitalista das ditas "sociedades modernas". Um princípio fundamental, utilizado por todos os autores da teoria crítica, era que o conhecimento da história deveria, incontornavelmente, ser a fonte de compreensão das estruturas e interações socioculturais que estabeleceram as relações de dominação e de exclusão ${ }^{36}$.

Sob tal ótica, ao pensar a saúde global a bioética crítica considera que o processo histórico de colonização dos continentes americano, africano e asiático, com a destrutiva exploração de suas riquezas, escravização de seus povos e estimulação de guerras étnicas, além de ter favorecido o enriquecimento da Europa foi, em grande parte, responsável pelos problemas hoje apresentados na qualidade política da governança, nas disparidades sociais e na baixa renda da maioria das ex-colônias, o que se reflete nas atuais condições de saúde da população global.

Como observado anteriormente, a bioética global de Potter, ao analisar a transformação da "mera sobrevivência" dos povos tradicionais em "sobrevivência miserável", responsabilizou justamente a ação dos colonos brancos ${ }^{13}$ - e de seu modelo de desenvolvimento - pelos danos das doenças, guerras e destruição ambiental que atingem a maior parte do planeta. Entretanto, Potter não aprofundou a análise da influência desses processos históricos na geração dos problemas transnacionais atualmente estabelecidos, nem em seus possíveis acordos na direção das melhorias da saúde humana e da sobrevivência planetária. Por sua vez, as formulações teóricas de Engerlhardt e de Beuchamp e Childress foram construídas em uma perspectiva claramente a-histórica em relação ao processo de colonização moderna. 
A fundamentação da bioética crítica inicia por sua concepção epistemológica enquanto ética aplicada, e assim constituída por um componente analítico, de natureza interdisciplinar, por meio do qual se busca compreender determinado conflito ético envolvendo as ciências da vida, e por componente propositivo-prescritivo de natureza procedimental, com vistas à tomada de decisão sobre ações ou normas envolvendo práticas científicas ou gestoras ${ }^{31}$.

No primeiro destes componentes são utilizados como categorias analíticas alguns conceitos e ideias extraídas de autores de todas as gerações da teoria crítica, complementados por elementos dos estudos sobre colonialidade ${ }^{37-39}$. O componente prescritivo apoia-se mais especificamente em elementos extraídos da teoria do agir comunicativo ${ }^{40}$. Esta proposição de Habermas poderia ser aplicada em espaços públicos de discussão próprios à bioética, tais como conselhos nacionais ou internacionais de bioética, fóruns de discussão para elaboração de normativas de ética de pesquisa, comitês hospitalares de bioética e comitês de ética da pesquisa. Dentro dos limites impostos a um artigo científico exporemos brevemente conceitos, ideias e princípios dos referenciais que sustentam nossa fundamentação.

A primeira dessas ideias é a crítica operada por Horkheimer ${ }^{41}$ ao isolamento social da ciência na concepção da teoria tradicional de inspiração newtoniana/cartesiana. Esta confere ao cientista lugar de neutralidade, de simples observador externo do fato ou objeto que estuda. Dessa forma torna-o incapaz ou desinteressado em avaliar as consequências sociais dos resultados de seus estudos. 0 complexo científico-tecnológico-industrial, responsável em grande parte pela criação e distribuição de bens de saúde, nasce, segundo a teoria crítica, dessa concepção de ciência, que atrela à própria produção do conhecimento a geração de tecnologias capazes de serem exploradas pelo capitalismo na busca do crescimento de seus mercados.

A teoria crítica propõe o estabelecimento de elo epistêmico entre verdade de fato e verdade de valor na ciência. Ou seja, a ciência, ao investigar a natureza e as sociedades, deve estar moralmente motivada pela busca de emancipação dos grupos humanos submetidos ao sofrimento da exclusão e da exploração historicamente determinadas. A bioética crítica assume também este compromisso para as construções teóricas, práticas de análise e processos de tomada de decisão sobre, por exemplo, protocolos de pesquisa, aplicação de biotecnologias, políticas públicas, programas de cooperação internacional em saúde, além da formulação de normas e diretrizes éticas em suas diversas aplicações.

Embora possa ser afirmado que as crenças axiológicas e axiomáticas da teoria crítica não têm maior validade epistêmica, per se, do que as crenças do paradigma científico tradicional, a adoção daquele referencial para a bioética crítica advém justamente da nossa compreensão quanto a sua legitimidade ética, isto é, do seu compromisso moral com a emancipação social dos grupos excluídos e explorados no processo de expansão da modernidade e do capitalismo.

Nessa perspectiva um conceito fundamental para a bioética crítica é o de racionalidade instrumental. A teoria crítica a define como forma de organização do pensamento que primeiro determina o fim a ser obtido e, depois, empreende todos os esforços de raciocínio para estabelecer estrategicamente as ações necessárias à obtenção deste fim, sem incluir qualquer reflexão sobre a moralidade dessas ações. É por essa forma de racionalidade que o ser humano orientou desde os tempos mais remotos seus esforços para o uso e domínio da natureza em seu favor. Entretanto, na modernidade, com o desenvolvimento do capitalismo a racionalidade instrumental tornou-se a forma de racionalidade típica dos poderes econômicos e políticos. Habermas descreve no nível subjetivo a colonização do mundo da $v^{\text {vida }}{ }^{40}$ pela racionalidade instrumental, a partir da qual os indivíduos tendem a agir mediante cálculos egoístas com vistas à realização de projetos pessoais em detrimento dos projetos coletivos.

Habermas irá também descrever a racionalidade comunicativa como forma de coordenar ações coletivas baseadas no diálogo livre entre os envolvidos em uma dada situação a regular, capaz de se opor à racionalidade instrumental desses poderes. As condições de intercompreensão entre os participantes de determinada discussão estaria apoiada no reconhecimento da validade dos argumentos dirigidos aos três mundos que conformam determinado universo de saber: o mundo objetivo ligado aos conteúdos de verdades verificáveis (empíricas ou científicas); o mundo social, ligado às características socioculturais e às normas de conduta formais ou informais no contexto da situação a regular; e o mundo subjetivo ligado à autenticidade dos participantes da discussão na demonstração de aceitação da força racional do melhor argumento. Além dessas exigências para o reconhecimento da validade dos argumentos, as consequências advindas da ação ou norma decidida no processo de discussão devem, se possível, ser aceitas por todos os envolvidos, livres 
de qualquer coação. Quando isso acontece, as decisões derivam em ações denominadas ações comunicativas e se opõem diretamente às ações estratégicas próprias à racionalidade instrumental ${ }^{40}$.

Por isso a bioética crítica, ao adotar a proposição habermasiana como base procedimental para o processo de tomada de decisão, se opõe tanto à negação da possibilidade de consensos coletivos da formulação procedimental de Engelhardt quanto à moralidade comum universal e seus princípios apriorísticos do modelo de Beauchamp e Childress. Por sua vez, a formulação teórica de Potter não chegou a propor qualquer via procedimental para a coordenação de ações no contexto da bioética global.

Como o próprio procedimento habermasiano apresenta alguns limites já reconhecidos desde a proposição inicial da bioética crítica ${ }^{31}$, propomos neste trabalho outro elemento importante para a construção desta perspectiva bioética, em especial quando dirigida a problemas na dimensão global. Trata-se da análise crítica de Robert $\operatorname{Cox}{ }^{42}$ sobre a formação das "ordens mundiais" e de seus desdobramentos políticos e econômicos que afetam todas as dimensões da vida, em todos os lugares do planeta, especialmente na formação de uma nova divisão social transfronteiriça formada por grupos "integrados", "precarizados" e "excluídos" da ordem mundial.

Embora este autor não tenha se filiado diretamente à escola de Frankfurt, desenvolveu sua teoria crítica em oposição à teoria tradicional da ciência, demonstrando como na modernidade as sociedades civis dominantes sustentam a formação de Estados que, por sua vez, moldam a ordem mundial por meio de relações de poder que expressam interesses correspondentes às próprias sociedades civis. Como nas últimas décadas do século $X X$ a globalização dos meios de produção resultou na coalização de uma sociedade civil dominante transnacional, os Estados também acabaram por internacionalizarem-se, submetidos ao poder regulador de uma rede volátil de interesses declarados e ocultos (chamada por Cox de nébuleuse) responsável pela "governança sem governo" da ordem mundial.

Segundo o autor, neste processo de relação entre poderes dominantes que se expressa em cada nível da estrutura hierárquica que vai da formação da sociedade civil, Estado e ordem mundial, prevalece o poder do grupo que detém instrumentalmente o controle simultâneo de três "forças": 1) capacidades materiais, representadas pelos recursos financeiros e meios de produção; incluindo a tecnologia 2 ) ideias, representadas pelas noções intersubjetivas sobre as relações sociais que tendem a perpetuar hábitos e comportamentos e imagens coletivas que legitimam as relações de poder; incluindo a ciência e a moral; e 3) instituições, responsáveis pela articulação de ideias e capacidades materiais com vistas a estabilizar e perpetuar determinada ordem, incluindo os diversos aparelhos do Estado.

Obviamente, no campo da saúde global a compreensão da gestão compartilhada entre Estados e grupos corporativos dominantes (em geral representados por grandes empresas e instituições regulatórias transnacionais) sobre a produção e distribuição de conhecimentos, geração de novas tecnologias e oferta de bens e serviços é indispensável à análise mais aprofundada das razões das discrepâncias em saúde e ao intuito de propor ações que venham alterar essa ordem em favor da emancipação dos grupos historicamente excluídos e precarizados.

Nesse sentido, a bioética crítica refuta as considerações de Engelhardt, para uma bioética global baseada em contratualismo liberal radical que busca apenas acordos interpessoais, que o autor, não por coincidência, denomina como mercado de interesses morais ${ }^{24}$. Em verdade, essa proposição apenas mascara as implicações das relações de poder que envolvem o encontro entre indivíduos, grupos ou países, e significa - a priori - o posicionamento em favor dos grupos historicamente privilegiados pelas relações de poder no cenário global.

Do mesmo modo, embora seja louvável o esforço de Beauchamp e Childress ${ }^{5}$ para incorporar preocupações sociais globais em seu princípio da justiça, a defesa do direito "mínimo" à saúde reproduz a lógica de exclusão à medida que moralmente aceita que pequenos grupos de indivíduos tenham pleno acesso aos bens e serviços de saúde, enquanto a maior parte da população planetária receba apenas um pacote "mínimo" de saúde arbitrariamente definido pelos que detêm o poder. Além disso, sua justificativa baseada em pretenso realismo e a preocupação com a "eficácia" do sistema global expressam a utilização de uma racionalidade tipicamente instrumental, que toma o modo de organização econômica atual como realidade impossível de ser alterada - e portanto apenas passível de ser remediada mediante a busca da redução de gastos.

É neste ponto que os estudos da colonialidade formulados na América Latina por autores como Quijano ${ }^{37}$, Mignolo ${ }^{38}$ e Grosfoguel ${ }^{39}$ acrescentam uma categoria analítica indispensável à nossa proposta de fundamentação para a bioética crítica, uma vez que, de certa forma, é negligenciada na concepção de modernidade da teoria crítica - referimo-nos a categoria de "raça". 
Quijano, por exemplo, concebe a colonialidade do poder como um mecanismo herdado no fim da colonização, legado e ainda impactante na geopolítica contemporânea. $\mathrm{Na}$ análise do processo de descolonização, o autor aponta que o elemento central que constituiu as relações entre os conquistadores europeus com seus colonos foi a noção hierarquizada de raça. Considerava-se que a estrutura biológica e mental dos povos colonizados representava sua "natural" inferioridade em relação aos europeus, o que legitimava a exploração, catequese e escravização. Atualmente, a colonialidade é a forma como se manteve atualizado o poder impositivo e normativo dos países centrais ao fim da colonização e que continua a ser exercido sobre a produção do conhecimento universalizável, além da conformação das próprias subjetividades.

Portanto, com vistas a examinar adequadamente os conflitos da bioética em questões como saúde global, ética da pesquisa internacional, destruição ambiental, produção e distribuição de biotecnologias, manutenção e aprofundamento das desigualdades, é indispensável somar aos referenciais da teoria crítica as proposições dos estudos da colonialidade quanto ao racismo estruturante da modernidade, algo que outras abordagens bioéticas que utilizam o referencial da escola de Frankfurt, como, por exemplo, a ética mínima de Adela Cortina ${ }^{43}$, não chegam a realizar.

No Brasil, Flor do Nascimento e Garrafa ${ }^{44}$ já haviam utilizado os estudos sobre colonialidade em diálogo com a bioética de intervenção, mas de forma geral a literatura nacional e internacional em bioética tem sido omissa ao analisar as influências da noção de raça na geração das iniquidades em saúde. Isto, em si, já pode ser considerado efeito da colonialidade do poder sobre esse campo de estudo.
De qualquer forma, entre as três perspectivas teóricas analisadas neste trabalho para pensar a bioética global, a de Engelhardt e a de Beauchamp e Childress foram completamente omissas quanto às implicações da colonialidade, e apenas a de Potter se aproximou, sem aprofundar-se, ao refletir sobre o papel do homem branco na exploração do ambiente e das comunidades tradicionais isoladas.

\section{Considerações finais}

Seguindo os pressupostos da teoria crítica e dos estudos da colonialidade, considera-se que uma bioética de inspiração crítica deve assumir que está diretamente envolvida na conformação dos conflitos globais de saúde, seja como instância de legitimação ou de questionamento da ordem políticoeconômica estabelecida.

Ao analisar a partir da abordagem da bioética crítica as chamadas bioéticas globais nas perspectivas de Potter, Engelhardt e Beauchamp e Childress, observamos, no caso dos dois últimos, total desconsideração com as relações históricas e políticas intrínsecas a qualquer relação geopolítica, especialmente em um campo tão sensível como a saúde. Mais do que manter situações persistentes de desigualdades em nível planetário, a desconsideração desses aspectos fundamentais para a formulação de uma bioética global apenas contribui para reforçar as iniquidades identificadas.

Por isso, compreendemos que a bioética necessita de uma fundamentação teórica criticamente comprometida com a superação dos condicionantes históricos e estruturais que mantêm a reprodução das desigualdades globais em saúde e que sempre ocorrem em prejuízo das pessoas e dos países periféricos ao sistema-mundo moderno/colonial.

Trabalho realizado a partir de pesquisa de tese a ser defendida no Programa de Pós-Graduação em Bioética da Universidade de Brasília (UnB).

\section{Referências}

1. Fortes PAC, Carvalho RRP, Tittanegro GR, Pedalini LM, Sacardo DP. Bioética e saúde global: um diálogo necessário. Rev. bioét. (Impr.). 2012;20(2):219-25.

2. Meireles ACPR, Oliveira CC. Bioética e saúde global: cuidados primários como instrumento de justiça social? Rev. bioét. (Impr.). 2012;20(1):208-14.

3. Demo P. Metodologia do conhecimento científico. São Paulo: Atlas; 2000.

4. Potter VR. Bioethics: bridge to the future. Englewood Cliffs: Prentice Hall; 1971.

5. Beauchamp TL, Childress JF. Principles of biomedical ethics. $7^{\mathrm{a}}$ ed. New York: Oxford; 2013.

6. United Nations Educational, Scientific and Cultural Organizations. Universal Declaration on Bioethics and Human Rights. [Internet]. Paris: Unesco; 2005 (acesso nov. 2013). Disponível: http://unesdoc.unesco.org/images/0014/001461/146180E.pdf 
7. United Nations Educational, Scientific and Cultural Organizations. Report of the International Bioethics Committee on social responsibility and health. [Internet]. Paris: Unesco/IBC; 2010 (acesso nov. 2013). Disponível: http://unesdoc.unesco.org/images/0018/001878/187899E.pdf

8. Semplici S. The importance of 'social responsibility' in the promotion of health. Med Health Care Philos. 2011;14(4):355-63.

9. ten Have H, Gordijn B. Travelling bioethics . Med Health Care Philos. 2011;14(1):1-3.

10. Potter VR. Global bioethics: building on the Leopold Legacy. Michigan: Michigan State University; 1988.

11. Potter VR, Potter L. Global bioethics: converting sustainable development to global survival. Med Glob Surviv. 1995;2(3):185-91.

12. Potter VR. Fragmented ethics and "bridge bioethics". Hastings Cent Rep 1999;29(1):38-40.

13. Potter VR, Potter L. Op. cit. p. 186.

14. Potter VR, Potter L. Op. cit. p. 187.

15. Potter VR, Potter L. Op. cit. p. 188.

16. Potter VR, Potter L. Op. cit. p. 189.

17. Potter VR. Op. cit. 1999. p. 40.

18. Engelhardt HT Jr. Bioética global: uma introdução ao colapso do consenso. In: Engelhardt HT Jr, organizador. Bioética global: o colapso do consenso. São Paulo: Paulinas: 2012. p. 19-40.

19. Engelhardt HT Jr. Op. cit. p. 21.

20. Engelhardt HT Jr. Op. cit. p. 22.

21. Delkeskamp-Hayes C. Implementação de direitos de assistência à saúde versus imposição de culturas de assistência à saúde. In: Engelhardt HT Jr, organizador. Op. cit. p. 114.

22. Engelhardt HT Jr. A busca de uma moralidade global: bioética, guerras culturais e diversidade moral. In: Engelhardt HT Jr, organizador. Op. cit. p. 53.

23. Erickson SA. Prefácio. In: Engelhardt HT Jr, organizador. Op. cit. p. 12.

24. Engelhardt HT Jr. A busca de uma moralidade global. Op. cit. p. 54.

25. Wildes KW. Bioética global e particular. In: Engelhardt HT Jr, organizador. Op. cit. p. 481.

26. Beauchamp TL, Childress JF. Op. cit. p. 3.

27. Beauchamp TL, Childress JF. Op. cit. p. 272.

28. Beauchamp TL, Childress JF. Op. cit . p. 277.

29. Beauchamp TL, Childress JF. Op. cit . p. 278.

30. Beauchamp TL, Childress JF. Op. cit. p. 294.

31. Lorenzo C. Teoria crítica e bioética: um exercício de fundamentação. In: Porto D, Garrafa V, Martins GZ, Barbosa SN. Bioéticas, poderes e injustiças: 10 anos depois. Brasília: CFM/Cátedra Unesco de Bioética/SBB; 2012. p. 173-89.

32. Andraos C, Lorenzo C. Sistema suplementar de saúde e internação domiciliar de idosos na perspectiva da bioética crítica. Rev. bioét. (Impr.). 2013;21(3):525-35.

33. Astraín R. Pensamiento crítico latinoamericano. In: Tealdi JC, director. Diccionario Latinoamericano de Bioética. Bogotá: Unibiblos/Unesco; 2008. p. 3-5.

34. Schramn F. Bioética da proteção: ferramenta válida para enfrentar problemas morais na era da globalização. Rev. bioét. (Impr.). 2008;16(1):11-23.

35. Garrafa V, Porto D. Intervention bioethics: a proposal for peripheral countries in a context of power and injustic. Bioethics. 2003;17(5-6):399-416.

36. Nobre M. Curso livre de teoria crítica. $3^{\mathrm{a}}$ ed. Campinas: Papirus; 2011.

37. Quijano A. Colonialidad del poder y clasificación social. In: Castro-Gómez S, Grosfoguel R. El giro decolonial: reflexiones para una diversidad epistémica más allá del capitalismo global. Bogotá: Siglo del Hombre Editores; 2007. p. 93-126.

38. Grosfoguel R. Para descolonizar os estudos de economia política e os estudos pós-coloniais: transmodernidade, pensamento de fronteira e colonialidade global. In: Santos BSS, Meneses MP, organizadores. Epistemologias do Sul. Coimbra: Edições Almedina; 2009. p. 383-417.

39. Mignolo W. Desobediência epistêmica: retórica de la modernidad, lógica de la colonialidad, gramática de la descolonialidad. Buenos Aires: Del Signo; 2010.

40. Habermas J. The theory of communicative action. London: Beacon Press; 1986.

41. Horkheimer M. Teoría crítica. Buenos Aires: Amarrortu Editores; 2003.

42. Cox RW. Social forces, states and world orders: beyond international relations theory. Millennium: Journal of International Studies. 1981;(2):126-55.

43. Cortina A. Ética mínima: introducción a la filosofía práctica. $6^{\text {a }}$ ed. Madrid: Tecnos; 2000.

44. Nascimento WF, Garrafa V. Por uma vida não colonizada: diálogo entre bioética de intervenção e colonialidade. Saúde Soc. 2011;20(2):287-99.

\section{Participação dos autores}

Trabalho derivado de tese de doutoramento. Os autores participaram igualmente de todas as fases da produção do artigo. Thiago Cunha na qualidade de discente doutorando, Cláudio Lorenzo como professor orientador.

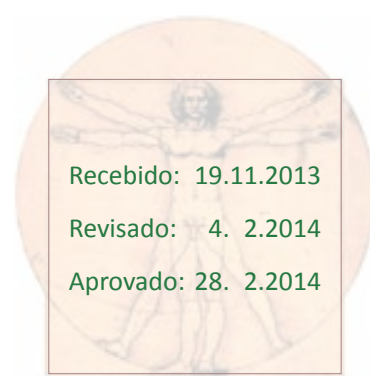

